\section{(- OPEN ACCESS}

\title{
Toothpick-induced aortoenteric fistula presenting as sepsis
}

\author{
Elizabeth Liao, ${ }^{1}$ Martin Simons, ${ }^{2}$ Leonard W Tse, ${ }^{3}$ Graham Roche-Nagle ${ }^{3}$
}

Faculty of Medicine, University of Toronto, Toronto, Canada ${ }^{2}$ Department of Medical Imaging, University of Toronto, Toronto, Canada

${ }^{3}$ Toronto General Hospital, Toronto, Canada

\section{Correspondence to} Dr Graham Roche-Nagle, graham.roche-nagle@uhn.ca

Accepted 30 May 2017

\section{SUMMARY}

Aortoenteric fistulas (AEF) are a rare but life-threatening cause of gastrointestinal (GI) bleeding. We present the case of a primary AEF caused by ingestion of a toothpick by a 47-year-old male. This is the 10th known case in the literature in which a foreign body was found to be the cause of a communication between the aorta and the GI tract. Most foreign objects have been sewing needles; this is the first known case of a toothpick penetration. The patient presented to our institution with polymicrobial sepsis and bilateral pulmonary septic emboli. The patient was successfully treated but required multiple interventions and a prolonged intensive care unit admission.

\section{BACKGROUND}

Aortoenteric fistulas (AEF) should be considered in gastrointestinal (GI) bleeds that are accompanied by sepsis. Secondary AEFs are well-known complications of any aortic reconstruction surgery with an incidence rate of approximately $1 \% .^{1}$ Primary AEFs, which arise de novo, are much rarer with an incidence around 0.007 per million. ${ }^{2}$ The most common cause of primary AEF is atherosclerosis $(80 \%)^{3}$; however, foreign bodies are an important cause of primary AEF and have been reported as the cause of GI bleed in patients as young as 3 years old. ${ }^{1}$

Detection of AEFs caused by foreign bodies is often delayed because they do not always present with overt bleeding. These lesions are difficult to visualise with endoscopy, and patients are often not aware of or forget about foreign body ingestion. Due to the high number of enteric bacteria, multiorganism bacteraemia can be the first presentation of these patients. Prompt antibiotic therapy and surgical correction are essential to avoid multiorgan failure and death.

\section{CASE PRESENTATION}

A 47-year-old male was admitted to our institution from a peripheral hospital. He had initially presented with a urinary tract infection and was subsequently found to have multiorganism bacteraemia. The patient was symptomatically septic. $\mathrm{He}$ was already intubated and on vasopressor support. At the peripheral hospital, he received CT scans, which showed thrombosis of the left renal vein with gas formation within it and phlegmonous changes around the left renal artery (figures 1 and 2). He was transferred to our institution for further evaluation. Repeat CT angiography confirmed a left proximal renal artery pseudoaneurysm behind the left renal vein with no tissue plane between the vessels and the duodenum. There was concern regarding a foreign body in the area and clot in the renal vein extending into the IVC (figure 1).

The patient's past medical history included non-insulin-dependent type II diabetes mellitus and body mass index of 40.7. He lived a sedentary lifestyle. He was on metformin and had no known drug allergies.

\section{OUTCOME AND FOLLOW-UP}

The patient was taken to the operating room for exploratory laparotomy. An on-table duodenoscopy confirmed a toothpick in the posterior wall of the third part of the duodenum, approximately $10 \mathrm{~cm}$ beyond the papilla, as the cause of the primary AEF.

Aortic control was achieved. The duodenum was mobilised, exposing the toothpick entering the renal vein and artery (figure 3 ). The renal vein was mobilised and controlled, and a thrombectomy was performed on the left renal vein and inferior vena cava to remove as much of the septic clot burden as possible. Interestingly, the thrombus in the renal vein was coloured green, due to the biliary staining and consistent with the septic pulmonary emboli. Formal division and ligation of the left renal vein allowed access to the left renal arteries, which was controlled distal to the left renal pseudoaneurysm. The injury to the artery was at the junction of the renal artery and aorta. Primary suture repair of the injury was performed. The duodenum was then repaired with multiple simple interrupted sutures and reinforced with a patch of omentum. The omentum was also secured into the abscess cavity and used to cover the arterial repair.

The surgical pathology report revealed recent and acute thrombus in the left renal aneurysm. On culture, the thrombus had a light growth of vancomycin-resistant Enterococcus faecium. Additionally, Enterobacter cloacae grew from the broth culture only.

Based on the sensitivities of the culture, the infectious disease service managed his antibiotic treatment postoperatively with meropenem, linezolid and tigecycline. A percutaneous tracheostomy was performed because of bilateral cavitary lung lesions due to septic emboli. Percutaneous drains were inserted by interventional radiology for persistent left retroperitoneal and para-aortic fluid collections. On postadmission day 15 , the patient underwent a left nephrectomy due to a non-resolving 


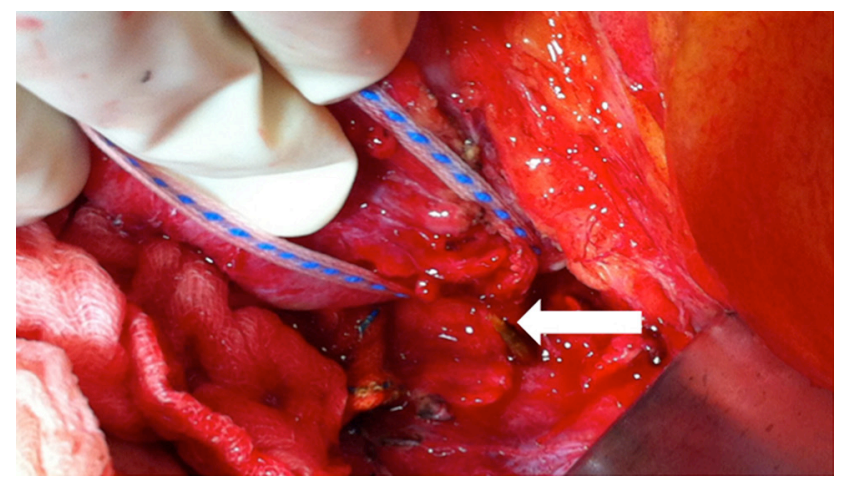

Figure $1 \mathrm{CT}$ abdomen showing thrombus in left renal vein (arrow).

abscess in the area. The patient remained in the ICU until day 27 when he was transferred to the step down unit. The patient was decannulated. Persistent IVC thrombus required intravenous heparin therapy. Cultures were negative at discharge and, as per infectious disease, no further antibiotics were required.

Three years later, the patient is alive but has not returned to his baseline functional status. He has not returned to work and is currently receiving disability benefits.

\section{DISCUSSION}

AEFs are rare, life-threatening events and so require a high index of suspicion. Although the most common cause of death in patients with AEF is massive bleeding, in this case we see that sepsis and multiorgan failure are equally as important to consider and prevent.

Diagnosing AEF can prove to be difficult. Primary AEFs occur in approximately 0.007 per million patients, and an even smaller fraction of those cases $(<20 \%)$ are caused by foreign bodies. The majority of primary AEFs occur in a subset of patients with history of atherosclerosis. However, the nature of a foreign body injury causing AEF makes this patient subpopulation unpredictable. The literature reports a case of foreign body AEF in a patient as young as 3 years old. ${ }^{1}$ Furthermore, patients often forget about ingestion of any foreign body since there may be a long delay between time of ingestion and time of injury. The first case of reported foreign body AEF in the literature describes a young man who most likely ingested a sewing needle in his infancy but who did not present until the

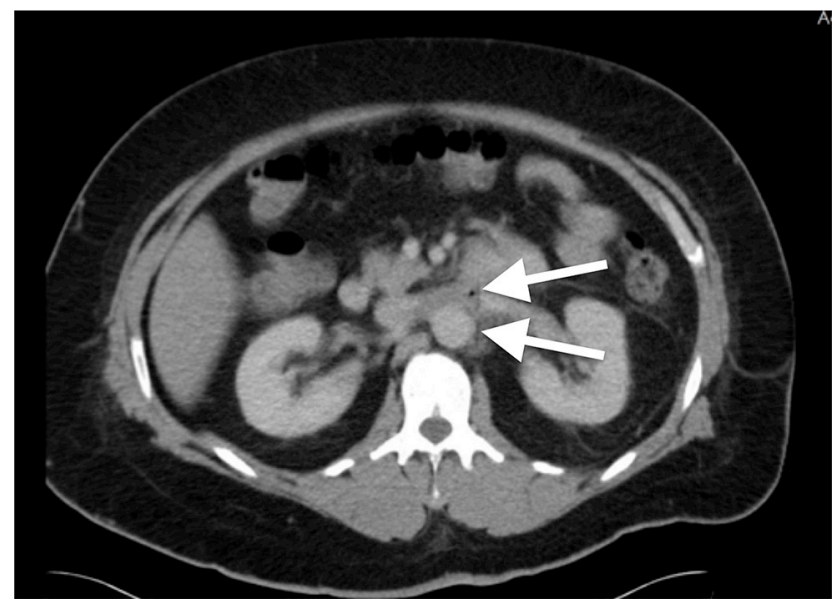

Figure 2 CT abdomen showing air visible next to wooden toothpick (arrows).

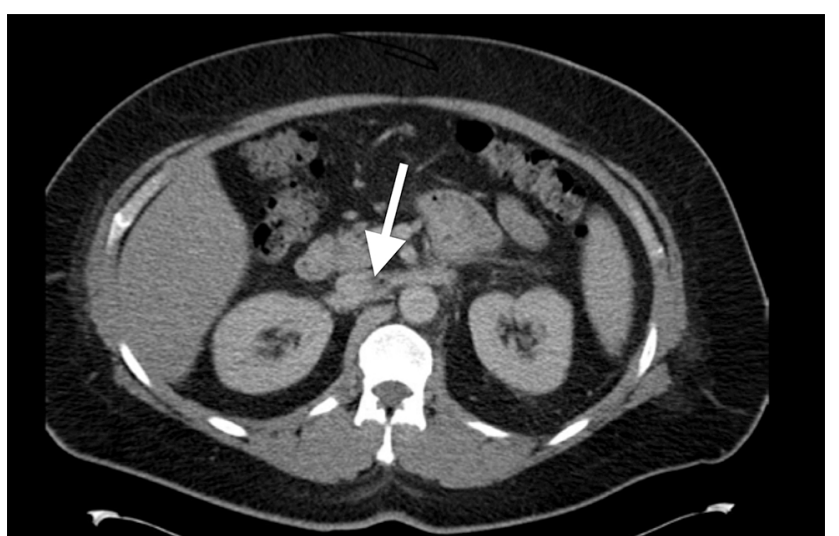

Figure 3 Intraoperative photo showing toothpick (arrow) penetrating duodenum. In this photograph, the duodenum has been lifted off of the toothpick, which remains fixed in the renal vein posteriorly.

age of $27 .{ }^{4}$ A literature review of accidentally ingested toothpicks showed that more than $50 \%$ of patients were not aware of the ingestion.

The most common clinical features of primary AEF are bleeding, abdominal pain and a palpable abdominal mass. Unfortunately, many reports have shown that this triad of symptoms is unreliable as it is only found in about a quarter of patients with AEF. ${ }^{1}$ AEFs are commonly mistaken for other causes of upper GI bleeding such as peptic ulcer disease, oesophageal or gastric varices and Mallory-Weiss tears. ${ }^{6}$

Most foreign body AEF cases in the literature have GI bleeding, whether it be haematemesis or positive fecal occult blood test, as the initial presentation. ${ }^{1478}$ The sentinel bleed is transient and self-limiting but largely important as it precedes the later catastrophic bleed. Additionally, the majority of sharp foreign body ingestions in the literature present with the chief complaint of abdominal pain. ${ }^{5}$ Our case is interesting because the patient did not present with abdominal pain nor bleeding, but rather with polymicrobial sepsis and pulmonary septic emboli. The number of different enteric micro-organisms makes bacteraemia and sepsis an important component of AEF.

Aortography is considered the gold standard to establish the diagnosis of AEF. Even so, contrast extravasation to the bowel is only seen in $26 \%$ of patients. ${ }^{3}$ Other methods of aortic imaging may also be used. In our case, CT angiogram was able to visualise the continuity between duodenum and renal artery. Endoscopy is not considered a strong diagnostic test for AEF. In some cases, the AEF will not be visible until exploratory laparotomy.

Surgical treatment of foreign body AEF entails removal of the foreign body, repair of the aorta and repair of the GI tract, usually in that order. There are several ways to repair the aortic defect, for which there is no general consensus. The literature reviewed favours prosthetic grafts, especially in the older population $^{179}$ Autologous vein graft seems to be preferred in the paediatric population due to its resistance to infection and size. ${ }^{8}$ One case report also describes use of split-thickness skin grafts to repair the aorta. ${ }^{10}$ In our case, primary suture closure was used in order to minimise cross clamp time and the desire not to leave foreign material in the presence of infection. Various techniques have had successes; therefore, repair technique of the aorta should be decided on a case-by-case basis.

Our case highlights the life-threatening consequences of a rare foreign body AEF. In our case, the foreign body was a seemingly harmless common household item. Proper diagnosis requires a very high index of suspicion and timely diagnostic imaging. 
Patient survival requires urgent surgical management, antibiotic therapy and long-term follow-up care.

\section{Learning points}

- Common household objects can be the cause of lifethreatening foreign body aortoenteric fistulas (AEF).

- Foreign body AEF can occur in patients of any age with any history, and therefore requires a high index of suspicion.

- Foreign body AEF may present without any bleeding symptoms, and a sepsis picture may be present.

- There are multiple techniques to repair the aorta during surgical management of AEF. The appropriate technique should be chosen on a case-by-case basis.

Contributors We certify that we have each made a significant contribution to the manuscript so as to qualify for authorship. EL reviewed the literature and was the primary author of the manuscript. LWT was the primary surgeon for the patient in the case and provided significant detail towards the patient's history and presentation. MS was responsible for the diagnosis of the toothpick-induced injury. GR-N was involved in the planning and guidance of the written manuscript. LWT, MS and GR-N were equally involved in the surgical and medical management of the patient in the case. They all contributed details to the manuscript. The final manuscript was reviewed and agreed on by all authors.

Competing interests None declared.

Patient consent Obtained.

Provenance and peer review Not commissioned; externally peer reviewed.

Open Access This is an Open Access article distributed in accordance with the Creative Commons Attribution Non Commercial (CC BY-NC 4.0) license, which permits others to distribute, remix, adapt, build upon this work non-commercially, and license their derivative works on different terms, provided the original work is properly cited and the use is non-commercial. See: http://creativecommons.org/ licenses/by-nc/4.0/

(C) BMJ Publishing Group Ltd (unless otherwise stated in the text of the article) 2017. All rights reserved. No commercial use is permitted unless otherwise expressly granted.

\section{REFERENCES}

1 Song $\mathrm{Y}$, Liu $\mathrm{Q}$, Shen $\mathrm{H}$, et al. Diagnosis and management of primary aortoenteric fistulas--experience learned from eighteen patients. Surgery 2008;143:43-50.

2 Tatco V, Skandhan AKP. Aorto-enteric fistula. 2016. http://radiopaedia.org/articles/ aorto-enteric-fistula (accessed 22 Aug 2016).

3 Saers SJ, Scheltinga MR. Primary aortoenteric fistula. Br J Surg 2005;92:143-52.

4 Hambrick E, Rao TR, Lim LT. Jejunoaortic fistula from ingested seamstress needle. Arch Surg 1979;114:732-3.

5 Steinbach C, Stockmann M, Jara M, et al. Accidentally ingested toothpicks causing severe gastrointestinal injury: a practical guideline for diagnosis and therapy based on 136 case reports. World J Surg 2014;38:371-7.

6 Cerulli MA, Iqbal S, Anand BS, et al. Upper gastrointestinal bleeding differential diagnoses. 2016. http://emedicine.medscape.com/article/187857-differential (accessed 27 July 2016).

7 Sevastos N, Rafailidis P, Kolokotronis K, et al. Primary aortojejunal fistula due to foreign body: a rare cause of gastrointestinal bleeding. Eur J Gastroenterol Hepatol 2002:14:797-800.

8 Kappadath SK, Clarke MJ, Stormer E, et al. Primary aortoenteric fistula due to a swallowed twig in a three-year-old child. Eur J Vasc Endovasc Surg 2010;39:217-9.

9 Voorhoeve R, Moll FL, Bast TJ. The primary aortoenteric fistula in The Netherlands-the unpublished cases. Eur J Vasc Endovasc Surg 1996;11:429-31.

10 Elledge ROC, Mohan D. A penetrating injury with a cocktail stick resulting in a spreading infection with Streptococcus milleri. BMJ Case Reports 2016 (accessed 21 Aug 2016).

Copyright 2017 BMJ Publishing Group. All rights reserved. For permission to reuse any of this content visit http://group.bmj.com/group/rights-licensing/permissions.

BMJ Case Report Fellows may re-use this article for personal use and teaching without any further permission.

Become a Fellow of BMJ Case Reports today and you can:

- Submit as many cases as you like

- Enjoy fast sympathetic peer review and rapid publication of accepted articles

- Access all the published articles

- Re-use any of the published material for personal use and teaching without further permission

For information on Institutional Fellowships contact consortiasales@bmjgroup.com

Visit casereports.bmj.com for more articles like this and to become a Fellow 